\title{
Food Crop Production Strategies for Adaptation to Climate Change in China -- A Modeling Study
}

\author{
Jin Zhiqing, Gao Liangzhi, Ge Daokuo, Chen Hua and Shi Chunlin \\ (Jiangsu Academy of Agricultural Sciences, Nanjing 210014, China)
}

\begin{abstract}
Several strategies for food crop production in China for adaptation to climate change were advanced, based on crop modeling experiments and related agroclimatic indices, under the equilibrium GCM climate change scenarios.

GISS and UKMO scenarios were respectively chosen for southern and northern China to conduct these experiments, because they seem to have had more dramatic effects on crop yields in these regions. The food crop simulation models including CERES series were validated for 23 sites in the main food crop planting areas of China to examine their suitability to simulate rice, winter wheat and maize production, using the local agronomic, soil and weather data for more than 3 successive years.
\end{abstract}

Key words: global climate change, China, food crop production, adaptation strategy.

\section{Background}

A doubled $\mathrm{CO}_{2}\left(2 \times \mathrm{CO}_{2}\right)$ climate change would result in a tremendous change both in temperature and precipitation conditions in China and would significantly affect Chinese food production.

During the international collaborative research program involving impacts of global climate change on world food crop production organized by the US EPA, the author et al (1992) used outputs of the 3 General Circulation Models, i.e., GISS, GFDL and UKMO equilibrium GCMs, in combination with the daily weather data in recent-years (1958-1986) at 23 representative sites (Fig.1) in the main food crop producing areas in China, to generate the local $2 \times \mathrm{CO}_{2}$ climate change scenarios for each sites.

Then the CERES-Rice (Ritchie et al., 1987), CERES-Wheat (Ritchie and Otter, 1985), CERESMaize (Jones and Kiniry, 1986) and SOYGRO (Jones et al., 1988) were selected to be validated and calibrated to examine their suitability for simulating the major food productions (including rice, winter wheat, maize and soybean) in those areas using the agronomic data taken from the local experiments for more than 3 successive years (usually from 1981-1986) and the daily weather data during the same period. The results indicated that there existed good agreements between the simulated and observed yields and, that these crop models were a powerful tool to assess the potential effects of climate change on food production in China (Jin et al., 1994a, 1994b, 1995, 1996).

The above crop simulation models were run again for the 23 locations for about 30 years (about 1958-1986) using the baseline climate data sets and the three $2 \times \mathrm{CO}_{2}$ climate change scenarios, with and without supplemental irrigation. The direct physiological effects of $\mathrm{CO}_{2}$ on food crop production were also included. Based on the modeling, the potential implications of climate change on food crop production in China were assessed (Jin et al., 1994a, 1994b, 1995, 1996).

In this paper, several strategies were developed for Chinese food crop production for adaptation to climate change, based on the modeling experiments as well as some agroclimatic indices. The GISS and UKMO climate change scenarios were selected respectively to conduct the experiments for southern and northern China, since they seem to be the ones with the most dramatic and negative effects on food crop yields in these regions. Soybean production was not included in this paper, because it is mainly distributed in the Northeast China and the North China Plains, where an increase in temperature is generally favorable to soybean production. Another reason is that soybean crop derives more benefit from an increase in $\mathrm{CO}_{2}$ than other food crops (Allen et al., 1987; Jin et al., 1994b).

\footnotetext{
Supported by China National Natural Science Foundation.
} 
1. Heihe

2. Harbin

3. Changchun

4. Yanji

5. Shenyang

6. Beijing

7. Shijiazhuang

8. Taiyuan

9. Jinan

10. Zhengzhou

11. Xian

12. Xuzhou

13. Nanjing

14. Hefei

15. Chengdu

16. Wuhan

17. Nanchang

18. Changsha

19. Guiyang

20. Fuzhou

21. Shaoguan

22. Kunming

23. Guangzhou

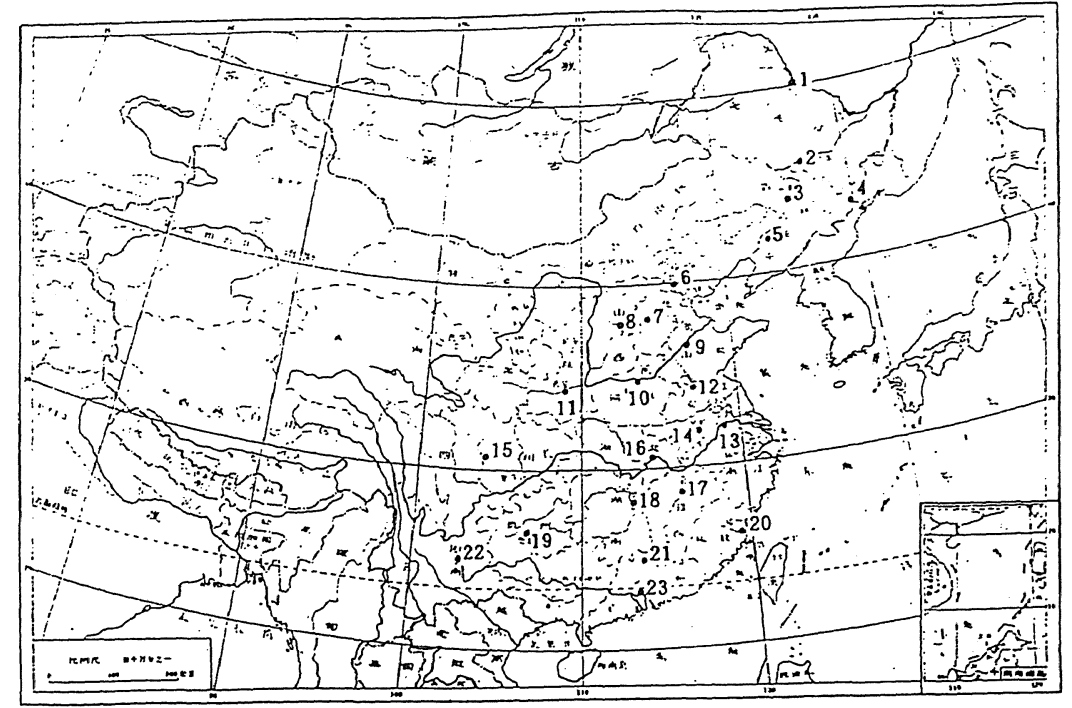

Fig.1. Distribution of the 23 representative sites in the main food crop producing areas in China

\section{Strategy Making}

(1) Strategy 1: increase of cropping index and reformation of cropping systems

Multiple cropping ( 2 or 3 crops per year) has been established in China for a long time. Now, it plays a very important role to support more than $20 \%$ of the world's population, with only about $7 \%$ of the world's cultivated land.

Temperature is one of the most important environmental factors to determine the local cropping systems in the main food production areas in China (Gao et al., 1987). Table 1 gives changes in the accumulated temperature with a base temperature of $10^{\circ} \mathrm{C}$ under the current climate (BASE) and the two climate change scenarios at the selected sites in the main food crop producing areas in China. These were generated from outputs of the GISS and UKMO GCMs $\left(2 \times \mathrm{CO}_{2}\right)$, in combination with the local daily historic climate data for about 30 years (1958-1986).

In this section, the possibility of increasing the cropping index and to reform the cropping systems for adaptation to climate change was analyzed employing several accumulated temperature indices.

- Rice

According to the China National Rice Research Institute (1988), the indices of annual accumulated temperature with a base temperature of $10^{\circ} \mathrm{C}$ for different rice-based cropping systems are as follows:

Single rice: $\Sigma \mathrm{T}_{\geq 10^{\circ} \mathrm{C}}$ is 2,000 to $4,500{ }^{\circ} \mathrm{C}$;

Double rice: $\Sigma \mathrm{T}_{\geq 10^{\circ} \mathrm{C}}$ is 4,500 to $7,000^{\circ} \mathrm{C}$, and the safe northern limit for double rice is $5,300{ }^{\circ} \mathrm{C}$;

Triple rice: $\Sigma \mathrm{T}_{210^{\circ} \mathrm{C}}$ is more than $7,000^{\circ} \mathrm{C}$.

- Winter wheat

To classify the major wheat-based cropping systems in China, Cui (1987) and Han (1991) used the following climatic indices:

Winter wheat + Maize: $\Sigma \mathrm{T}_{\geq 0^{\circ} \mathrm{C}}$ is 4,500 to $4,900^{\circ} \mathrm{C}$, precipitation is about $800 \mathrm{~mm}$;

Winter wheat + Rice: $\sum \mathrm{T}_{20^{\circ} \mathrm{C}}$ is 4,500 to $5,500^{\circ} \mathrm{C}$, precipitation is about $800 \mathrm{~mm}$;

Wheat + Double rice: $\sum \mathrm{T}_{20^{\circ} \mathrm{C}}$ is 5,900 to $7,300^{\circ} \mathrm{C}$, Precipitation is more than $1,000 \mathrm{~mm}$

- Maize

The actual distribution of spring-, summer- and autumn maize in the China Maize Belt is determined not only by the local cropping systems, but also by temperature. The indices of annual 
accumulated temperature with a base temperature of $10^{\circ} \mathrm{C}$ used to classify different maize zones in China are given as follows (Cui, 1984, 1991; Dong, 1992; Liu et al., 1993):

Spring maize zone: $\sum \mathrm{T}_{\geq 10^{\circ} \mathrm{C}}$ is less than $3,500^{\circ} \mathrm{C}$;

Summer maize zone: $\sum \mathrm{T} \geq 10^{\circ} \mathrm{C}$ is more than $3,500^{\circ} \mathrm{C}$, but less than $5,300{ }^{\circ} \mathrm{C}$;

Autumn maize zone: $\Sigma \mathrm{T}_{\geq 10^{\circ} \mathrm{C}}$ is more than $5,300^{\circ} \mathrm{C}$.

Table 1 Changes in annual accumulated temperature with a base temperature of $10^{\circ} \mathrm{C}$ under current climate (BASE) and the three $\left(2 \times \mathrm{CO}_{2}\right)$ climate change scenarios in China.

\begin{tabular}{lcccc}
\hline Site & Latitude & \multicolumn{1}{c}{ BASELINE } & GISS & UKMO \\
\hline Heihe & $50^{\circ} 26^{\prime}$ & 2170 & 2879 & 3705 \\
Harbin & $45^{\circ} 41^{\prime}$ & 2792 & 3641 & 4777 \\
Changchun & $43^{\circ} 52^{\prime}$ & 2977 & 3837 & 5030 \\
Shenyang & $41^{\circ} 46^{\prime}$ & 3518 & 4287 & 5747 \\
Beijing & $39^{\circ} 48^{\prime}$ & 4217 & 5197 & 6352 \\
Shijiazhuang & $38^{\circ} 00^{\prime}$ & 4585 & 5819 & 6827 \\
Taiyuan & $37^{\circ} 47^{\prime}$ & 3569 & 4773 & 5677 \\
Jinan & $36^{\circ} 41^{\prime}$ & 4943 & 6240 & 7254 \\
Zhengzhou & $34^{\circ} 43^{\prime}$ & 4790 & 6152 & 7160 \\
Xuzhou & $34^{\circ} 19^{\prime}$ & 4529 & 5967 & 6985 \\
Xian & $34^{\circ} 18^{\prime}$ & 4528 & 5871 & 7142 \\
Nanjing & $32^{\circ} 00^{\prime}$ & 5076 & 6565 & 7598 \\
Chengdu & $30^{\circ} 40^{\prime}$ & 5322 & 7330 & 8216 \\
Wuhan & $30^{\circ} 37^{\prime}$ & 5433 & 7634 & 8038 \\
Nanchang & $28^{\circ} 36^{\prime}$ & 5831 & 7237 & 8290 \\
Changsha & $28^{\circ} 12^{\prime}$ & 5731 & 7905 & 8103 \\
Guiyang & $26^{\circ} 34^{\prime}$ & 4868 & 7242 & 7650 \\
Fuzhou & $26^{\circ} 05^{\prime}$ & 6740 & 8294 & 9404 \\
Kunming & $25^{\circ} 02^{\prime}$ & 4768 & 6939 & 7366 \\
Shaoguan & $24^{\circ} 48^{\prime}$ & 7011 & 9465 & 8470 \\
Guangzhou & $23^{\circ} 08^{\prime}$ & 7745 & 9148 & 9170 \\
\hline Mean & - & 5289 & 6812 & 7557 \\
\hline
\end{tabular}

Referring to the above-mentioned indices and Table 1, it is clear that the annual accumulated temperature with a base temperature of $10^{\circ} \mathrm{C}$ in the main food producing areas of China would increase under these two scenarios. This would lead to an extension of crop growing seasons and a significant reduction of crop life cycles. The combined effects would shift the northern limits for various cropping systems toward higher latitudes and be favorable to increase the cropping index in China.

For the rice crop, the northern limits for double and triple cropping of rice in China would shift northward about 5-10 degrees latitude depending on the climate scenario analyzed (Fig.2). As to winter wheat, the northern limit would shift northward from the current line along the Great Wall up to a new position shown in Fig.3.

Under the GISS scenarios, the cropping systems in the north of the Huang-Huai-Hai (H.H.H.) Plain would change from a single crop or three crops in two years (winter wheat $\rightarrow$ soybean $\rightarrow$ spring maize etc.) at the present time to two crops (winter wheat + maize, or winter wheat + cotton) per year and that in the south of the H.H.H. Plain, would change from two crops (winter wheat +

rice, or winter wheat + maize etc.) per year to dryland triple-cropping under the climate change condition. Also, the cropping pattern of "wheat + double rice" would likely be possible in areas where water supply is available. In the Middle and Lower Valley of the Yangtze River, "wheat + double rice" and triple rice would be the major cropping patterns. In Sichuan, double or triple rice could be grown in the basins or areas with a perfect irrigation condition. In the mountainous regions, however, dryland triple- cropping is likely to dominate, because of the drier climate. In southern China, triple rice could be grown throughout the year. The UKMO scenario gives an extreme case, and it will not be discussed in detail in this section.

Based on the above analysis, increase in cropping index, as an effective strategy for adapting to climate change, would be required to mitigate the potential impacts on reduction of rice production. 


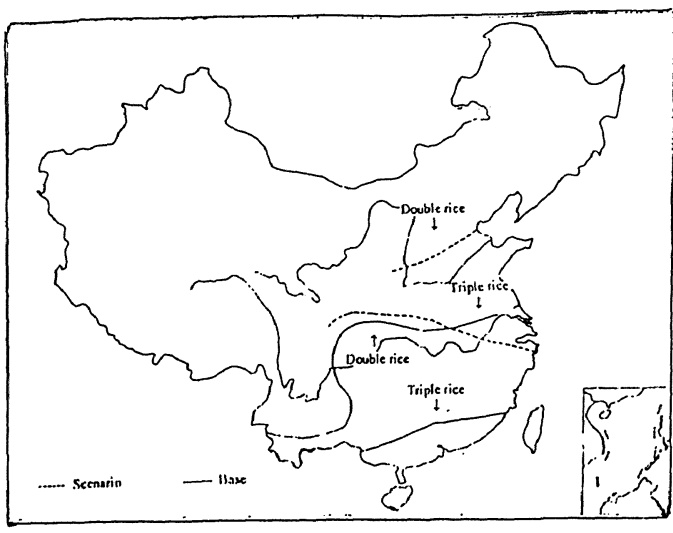

Fig.2. Geographic shift of the safe northern limits for double- and triple-rice crops in China under the GISS scenario, compared with the base.

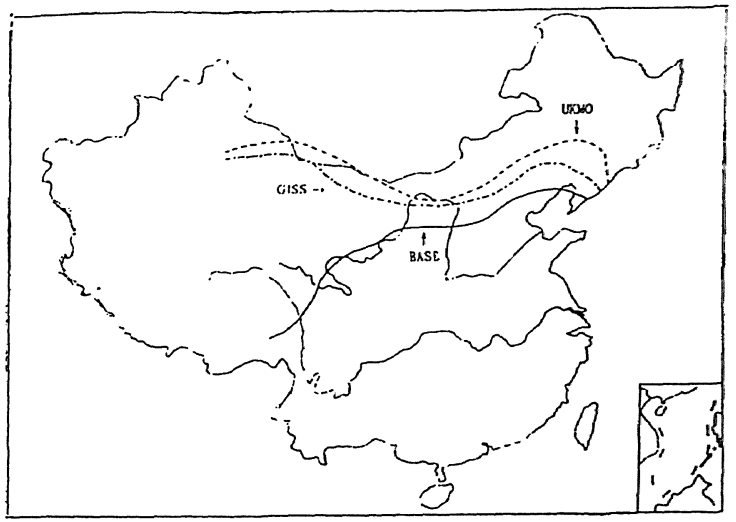

Fig.3. Geographic shift of the safe northern limit for winter wheat in China under the GISS and UKMO scenarios, compared with the base.

\section{(2) Strategy 2: Regulation of varietal disposition}

With an increase of temperature, a great change in varietal disposition would occur in the main food crop producing areas in China.

\section{- Rice}

Under the GISS and UKMO climate change scenarios, a large increase in temperature would result in advancing the rice maturity date (Jin et al.,1995) and the current rice distribution pattern so called "the south indica and the north japonica" would be changed. This means rice varieties with a longer growth duration and which are more high temperature-tolerant would dominate not only in the southern China, but also partially in northern China.

\section{- Winter wheat}

There are four typical varietal types for winter wheat in China, i.e., strong winter, winter, semi-winter and spring. Each of them is adaptable to specific climatic conditions (Table 2). For a given varietal type, only after undergoing a cold period for vernalization in its early stage, can it develop from vegetative growth to reproductive growth. This means the local cultivars would be changed from strong winter wheat to winter wheat in the northern parts of the H.H.H Plain and from winter wheat to semi-winter in the southern parts, due to lack of cold winter temperatures. In the Yangtze River Valley, the currently used cultivars with semi-winter characteristics would be replaced by that with spring characteristics.

- Maize

The indices of annual accumulated temperature with a base temperature of $10^{\circ} \mathrm{C}$ for requirements of different maize patterns in China Maize Belt are given as follows (Cui et al., 1984, Cui, 1991; Liu and $\mathrm{Mu}, 1993)$ :

Early maize: $\Sigma \mathrm{T}_{210^{\circ} \mathrm{C}}$ is 1,800 to $2,200^{\circ} \mathrm{C}$;

Medium maize: $\Sigma \mathrm{T}_{\geq 10^{\circ} \mathrm{C}}$ is 2,200 to $2,600^{\circ} \mathrm{C}$;

Late maize: $\Sigma \mathrm{T}_{210^{\circ} \mathrm{C}}$ is more than $2,600^{\circ} \mathrm{C}$. 
Table 2 Agroclimatic indices for winter wheat in China (Source: Cui, 1987)

\begin{tabular}{lcc}
\hline Varietal type & $\begin{array}{c}\text { Mean daily temp. required } \\
\text { for vernalization }\left(\text { in }{ }^{\circ} \mathrm{C}\right)\end{array}$ & $\begin{array}{c}\text { Accumulated } \\
\text { num. of days }\end{array}$ \\
\hline Strong winter & $0-3$ & $\geq 45$ \\
Winter & $0-3$ & $<45$ \\
& $0-7$ & $30-45$ \\
Semi-winter & $0-7$ & $15-30$ \\
Spring & $0-12$ & $<15$ \\
\hline
\end{tabular}

According to the above indices and Table 1, it can be seen that, at the present time, only the spring maize can be grown north of the line from Taiyuan to Shenyang where the thermal condition is not so sufficient. Summer maize can, but autumn maize can not, be grown between the line mentioned above and another line from Chengdu to Changsha. When $\mathrm{CO}_{2}$ is doubled (555ppm), summer maize could be grown at Harbin under the GISS scenario, and there would be no northern limit for summer-sowing maize in China under the UKMO scenario. As to autumn maize, it could be developed up to the line from Xian to Shijiazhuang, according to the GISS scenario, and up to the line from Taiyuan to Shenyang according to the UKMO scenario. With respect to varietal disposition, the current varieties with early or medium maturity would be replaced by those with late maturity.

These results suggest that regulating varietal disposition would also be one of the most effective strategies for adapting to climate change in China.

\section{(3) Strategy 3: Improvement of the irrigation system}

This strategy was made, based on the simulation experiment in which the rainfed and irrigated crop yields under climate change conditions were compared at selected sites, to determine if irrigation would mitigate the negative effects of climate change on crop yields.

\section{- Rice}

Chengdu and Guangzhou under the GISS scenario were chosen to conduct this simulation experiment, since the modeled rice yields under this scenario seem to sharply drop due to a large decrease in precipitation at these two locations during the rice growing season (Jin et al., 1995).

The results show that the rainfed rice yields at Chengdu and Guangzhou would decrease $72 \%$ and $45 \%$, compared to the base yields and the irrigated rice yields at the two sites declined only $32 \%$ and $16 \%$, respectively. On the other hand, the yield stability under rainfed conditions was less than that under irrigation conditions. These suggest that as an effective strategy for adapting to climate change, it would be necessary to improve the irrigation systems especially in areas where the projected precipitation during rice growing season would greatly decrease under climate change conditions.

The simulation results also show that the amount of evapotranspiration for rainfed rice is usually less than that for irrigated rice. It is likely that upland rice would be developed in areas where irrigation water is not available.

\section{- Winter wheat}

The H.H.H. Plain was selected to conduct the simulation experiments under the UKMO scenario. The results indicate that full irrigation would be beneficial for wheat to partially ameliorate the negative effect of climate change and to raise the yield stability. At Jinan and Zhengzhou, for example, yield reduction in rainfed wheat reached $30 \%$ and $12 \%$, compared to the base yields, and that for irrigated wheat reached only $13 \%$ and $5 \%$, respectively. Of course, it is not so easy to improve irrigation conditions especially in the northern parts of the H.H.H. Plain, where water resources are highly limited. For this reason, constructing big reservoirs and diversion works should be included in the national long-term plan.

\section{- Maize}


Three sites (Harbin, Changchun and Shenyang) in the NE China Plain and six sites (Beijing, Taiyuan, Jinan, Zhengzhou, Xian and Xuzhou) in the H.H.H. Plain were selected to conduct this experiment under the UKMO scenario. The results show that full irrigation could not significantly improve maize yields in the NE China Plain, because the scenario precipitation is not a limiting factor in maize production. Similar results were also obtained in the H.H.H. Plain where the weather is rather dry and water resources are insufficient. A major reason for this might be that stomatal conductance in maize obviously decreases with increasing $\mathrm{CO}_{2}$, and its water use efficiency (WUE) greatly improved.

This suggests that properly developing maize in areas where irrigation water is not available might be one of the effective strategies for adapting to climate change, especially for drought.

\section{(4) Strategy 4: Introduction of new crop varieties}

This strategy considers whether new crop cultivars would improve the yield under climate change conditions.

- Rice

A new rice cultivar IR43 was simulated under a fully irrigated condition in 7 sites (see Table 3) under the GISS scenario. The results show that yields of the new cultivar were $6.4-39.6 \%$ higher than those of the originally used cultivar at most sites, but not all.

An upland rice cultivar (UPLR15) was simulated for Chengdu and Guangzhou where the projected precipitation declined dramatically under the GISS scenario. With the new cultivar, the yield at Chengdu under the GISS scenario increased significantly compared with that of the originally used cultivar, although it was still obviously lower than the baseline yield (see Table 3). At Guangzhou, however, introducing the same cultivar did not improve the yield under the scenario conditions. Similar analyses were not done for the other cultivars. Some of them might, however, be suitable for the Guangzhou case.

\begin{tabular}{|c|c|c|c|c|}
\hline Site & СС\% & $(\mathrm{CC}+\mathrm{C}) \%$ & $(\mathrm{CC}+\mathrm{PD}) 96$ & $(C C+P D+C) 96$ \\
\hline Nanjing & 3 & -2 & 14 & 0 \\
\hline Xuzhou & 6 & 10 & 10 & 11 \\
\hline Nanchang & -7 & 40 & 3 & 43 \\
\hline Wuhan & -3 & 6 & -1 & 21 \\
\hline Changsha & -12 & 10 & -10 & 25 \\
\hline Chengdu+ & -72 & -54 & - & -41 \\
\hline Fuzhou & -4 & 29 & -2 & 30 \\
\hline Shaoguan & -3 & -1 & 5 & 3 \\
\hline Guangzhou ${ }^{+}$ & -32 & -47 & - & -36 \\
\hline Mean & -14 & -1 & 3 & 6 \\
\hline
\end{tabular}

+ rainfed, the others were automatic irrigation.

CC - climate change effect (GISS scenario).

$C C+P D$ - effects of climate change plus changing sowing date.

$C C+C$ - effects of climate change plus change in the cultivar.

$C C+P D+C$ - combination effect of climate change and changes both

in the sowing date and cultivar.

- Winter Wheat

Under the UKMO scenario, the local cultivars in northern part of the H.H.H. Plain were changed to Yangmai NO.5, a half-spring cultivar originating in Jiangsu province, and that in southern part of 
the Plain were changed to Mianyang No.11, a spring cultivar from Sichuan, then the CERES-Wheat was run again. Meanwhile, a foreign cultivar, SST, was introduced to both the Middle and Lower Valley of the Yangtze River and the Sichuan Basin under the GISS scenario. The results shown in Table 4 indicate that the new varieties could largely improve the yields in most sites, but not in southern part of the H.H.H. Plain and the Sichuan Basin.

\begin{tabular}{|c|c|c|c|c|c|}
\hline $\begin{array}{l}\text { Region's } \\
\text { Name }\end{array}$ & $\begin{array}{l}\text { Representative } \\
\text { location }\end{array}$ & CC\% & $(\mathrm{CC}+\mathrm{C})$ \% & $(\mathrm{CC}+\mathrm{PD})$ 品 & $(\mathrm{CC}+\mathrm{PD}+\mathrm{C}) 9$ \\
\hline \multirow{7}{*}{$\begin{array}{l}\text { The H.H.H. } \\
\text { Plain }\end{array}$} & Beijing & -3.9 & 7.6 & -3.1 & 9.4 \\
\hline & Taiyuan + & -17.8 & 44.4 & -17.6 & 46.2 \\
\hline & Xian & -8.7 & 13.2 & -8.7 & 61.5 \\
\hline & Jinan & -13.1 & 85.7 & -12.4 & 124.8 \\
\hline & Zhengzhou & 1.1 & -9.8 & 2.9 & -9.1 \\
\hline & Xuzhou & 0.9 & -54.2 & 3.6 & 4.3 \\
\hline & & $(-6.9)$ & $(14.5)$ & $(-5.9)$ & $(39.5)$ \\
\hline \multirow{4}{*}{$\begin{array}{l}M \text { \& } L \text { of } \\
\text { Yangtze } R \text {. }\end{array}$} & Nanjing + & -8.3 & 33.7 & -7.9 & 97.7 \\
\hline & Wuhan + & -6.2 & 48.6 & -5.4 & 48.6 \\
\hline & Changsha+ & 2.6 & 27.6 & 6.5 & 28.8 \\
\hline & & $(-4.0)$ & $(36.7)$ & $(-2.7)$ & $(58.4)$ \\
\hline \multirow[t]{2}{*}{ Sichuan } & Chengdu & 22.2 & 1.9 & 34.4 & 2.9 \\
\hline & & $(22.2)$ & $(1.9)$ & $(34.4)$ & $(2.9)$ \\
\hline
\end{tabular}

+ Rainfed, the others were irrigated

CC - Climate change effect alone

$C C+C$ - Combined effects of climate change plus change in cultivar.

$C C+P D$ - Combined effects of climate change plus change in sowing date.

$\mathrm{CC}+\mathrm{PD}+\mathrm{C}-\mathrm{Combined}$ effects of climate change and changes both in sowing date and cultivar.

\section{- Maize}

Three foreign maize cultivars, i.e., GARST 8808, PB-8 and DEKALB XL 45 were respectively simulated under the UKMO scenario. The results indicate that the simulated yields of new varietics increase $132 \%, 127 \%$ and $107 \%$, compared with the originally used cultivar under the same scenario, and also increase $24 \%, 21 \%$ and $10 \%$, compared to the baseline yield.

In summary, one of the most effective strategies for adapting to climate change is to develop or introduce new crop cultivars which have a longer growth duration and more heat, drought and pest resistances.

\section{(5) Strategy 5: Adjustment of planting dates}

In this modeling experiment, only the local sowing dates of the present cultivars for various crops were adjusted (using a 10-days step length). The CERES models were further run under the GISS or UKMO scenarios, depending on the site selected, to see if the modeled the modeled crop yields would be improved adopting this strategy under the climate change conditions. 


\section{- Rice}

Seven sites in southern China were selected to conduct this experiment under the GISS scenario. The results shown in Table 3 indicate that an appropriate change in the local planting date would cause an increase in rice yield for the northern sites (Xuzhou and Nanjing), but not for the southern sites.

\section{- Winter wheat}

The simulation results show that with the GISS scenario, a proper change in the sowing date alone could cause a $12.2 \%$ yield increase, compared with that of the originally used sowing date in the Sichuan Basin. The reason might be that the filling stage, in a certain degree, avoided the hightemperature period. But in the other regions, no significant increase in wheat yield could be found when adopting the same strategy (see Table 4).

\section{- Maize}

The results for most selected sites indicate that advancing the local sowing date in a proper manner could, but not significantly, mitigate the negative effect of increased temperature during the filling stage. However, the reduction of yields would be dramatically improved from a $25 \%$ decrease to only a $3 \%$ decrease compared with the base yields, if postponing the originally used sowing dates for $1-2$ months, i.e., adopting summer-sowing instead of spring-sowing in the NE China Plain, and using autumn-sowing instead of summer-sowing in the H.H.H. Plain. One interpretation for this is that a large temperature difference in autumn might be favorable for maize filling. Similar results could be obtained in the SW China Maize Zone.

The results mentioned above suggest that a proper change in local sowing dates under the climate change condition would increase crop yields at many sites, but not all.

\section{(6) Strategy 6: Changes in both Cultivars and Planting Dates}

This strategy is a combination of strategy 4 and strategy 5 . The simulation results indicate that more significant increases in crop yield could be obtained by adopting this combined strategy.

\section{Discussion}

Facing the challenge of global climate change, the possible adaptation strategies which could be chosen in Chinese food crop production are many and varies, including but not limit to the ones mentioned above. For example, reformation of the energy construction, population control, afforestation and forestry protection, environment improvement, rational use of fertilizer, pesticide and herbicide, rotation of paddy rice and upland crops, etc., might be very effective in reducing emission of greenhouse gases. Besides, it is necessary for China to enhance its comprehensive studies on water and soil conservation, land-use, crop pest control, especially on climate change and weather disasters, etc. All of these are favorable for China to develop its sustainable food production under the changing climate condition. 


\section{References}

Allen, L.H., Boote, K.J.Jr., Jones, J.W., Jones, P.H., Valle, R.R., Acock, B., Rogers, H.H., and Dahlman, R.C., 1987: Response of vegetation to rising carbon dioxide: photosynthesis, biomass and seed yield of soybean. Global biogeochemical cycles, 1, 1-14.

China National Rice Research Institute,1988: A classification for rice planting in China (in Chinese). Zhejiang Sci. and Tech. Publishing House, Hangzhou, 1-49.

Cui, D. C., Liu, H.S., Ming, J. R., and He, J. M., 1984: Climatic resources atlas for major crops in China (in Chinese). Met. Publishing House, Beijing, 119-156.

Cui, D. C., 1987: A climatic classification for agricultural and forest crops in China (in Chinese). Met. Publishing House, Beijing, 4-35.

Cui, D.C., 1991: Climate and food production - maize (in Chinese). In Climate and agriculture in China (ed. by C. S. Cheng). Met. Publishing House, Beijing, 205-223.

Dong, P.Y., 1992: A classification for maize planting in China (in Chinese). Agr. Publishing House. Beijing, $383 p$

Gao, L. Z., Li, L., and Jin, Z. Q., 1987: A classification for rice production in China. Agr. and Forest. Met., $39,55-65$.

Han, X.L., 1991: Climate and cropping system (in Chinese). In Climate and agricultural in China (ed. by C.S. Cheng). Met. Publishing house, Beijing. 127-160.

Institute of Soil Science, Academic Sinica, 1986: The soil atlas of China. Cartographic Publishing House, Beijing, 9-18.

Jin, Z.Q., Chen, H., Ge, D.K., and Fang, J., 1992: Generating climate change scenarios with doubled $\mathrm{CO}_{2}$ in China using GCMs outputs and historic weather data (in Chinese). China Agr. Met. 13, 13-20.

Jin, Z. Q., Fang, J., Ge, D. K., Zheng, X. L., and Chen, H.,1994: Prospect to the impacts of climate change on winter wheat production in China (in Chinese). ACTA Agronomic Sinica. 20, 186-197.

Jin, Z. Q., Ge, D.K., Zheng X.L., and Chen, H.,1994: Positive and negative effects of global climate change on soybean production in China (in Chinese). J. Soybean Science. 13, 302-311.

Jin, Z.Q., Ge, D.K., Fang, J., and Chen, H., 1995: Effects of climate change on rice production and strategies for adaptation in southern China. In Climate change and agriculture: Analysis of potential international impacts (ed. by Rosenzweig, C. et al). ASA Special Publication, 59, 307-324.

Jin, Z.Q, Ge, D.K., Zheng, X.L., and Chen, H., 1996: Assessing the potential impacts of global climate change on maize production in China (in Chinese). ACTA Agronomic Sinica. 22, 513-524.

Jones, C. A., and Kiniry, J. R., 1986: CERES-Maize - A simulation model of maize growth and development. Texas A \& M University Press, College Station, TX. 194p.

Jones, J. W., K. J. Boote, S. S. Jagtap, and G.G. Wilkerson. 1988: SOYGRO V5. 41: Soybean crop growth simulation model. User's Guide. Florida Agr. Exp. Sta. J. No. 8304, IFAS. Uni. of Florida. Gainesville. $53 \mathrm{p}$.

Liu, X.H., and Mu, Z.G., 1993: Chinese farming system (in Chinese). Agi. Publishing House, Beijing, 565p.

Ritchie, J.T., and Otter, S., 1985: Description and performance of CERES-Wheat: A user-oriented wheat yield model. In ARS Wheat Yield Project (ed. by Willis, W.O.) USDA-ARS. ARS-38, 159-175.

Ritchie, J. T., Alocilja, E. C., Singh, U., and Uehara, G., 1987: IBSNAT and the CERES-Rice model. In Weather and Rice. IRRI, Manila, Philippines, 271-281.

Xiong, Y., and Li, Q.K., 1987: Chinese Soils (2nd Edition). Sci. Publishing House, Beijing, 746p. 
$-758-$ 